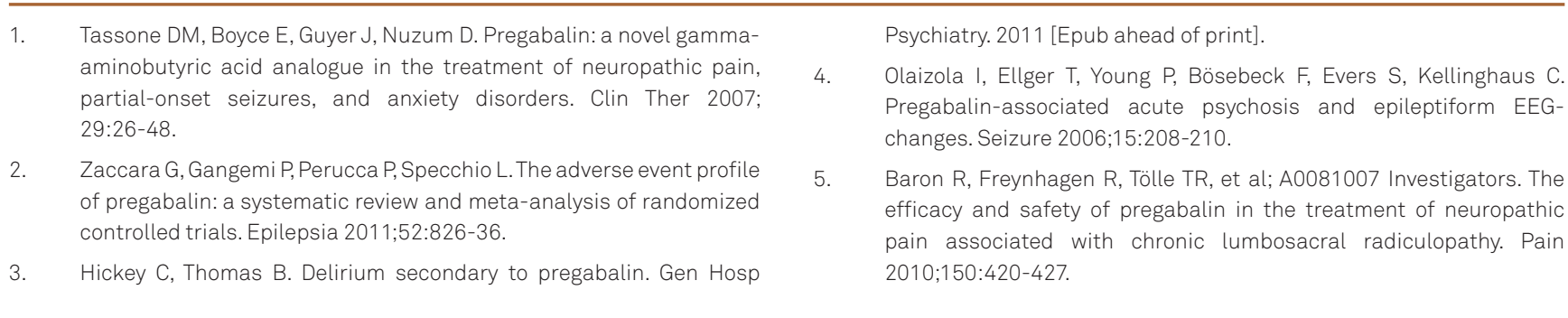

\title{
Recurrent post-ictal hyperthermia
}

\author{
Hipertermia pós-ictal recorrente
}

\author{
Sofia Rocha, Filipa Sousa, João Pinho, Ricardo Maré, Álvaro Machado
}

Department of Neurology, Hospital of Braga, Braga, Portugal.

Correspondence: Sofia Rocha; Serviço de Neurologia, Hospital de Braga; Sete Fontes / São Victor; 4710 -243 Braga - Portugal; E-mail: sofiarocha99@hotmail.com Conflict of interest: There is no conflict of interest to declare.

Received 14 May 2012; Received in final form 18 May 2012; Accepted 29 May 2012

Hyperthermia is a well-known precipitant of seizures, especially in susceptible individuals and in children ${ }^{1,2}$. Its occurrence following epileptic seizures or exclusively peri-ictally is rarely described ${ }^{2}$.

\section{CASE REPORT}

An 80-year-old hypertensive man, with epileptic seizures of unknown etiology, since his 70th's, was observed for 3 times in 4 years with self-limited right focal motor seizures with impairment of consciousness. In all these episodes, he had post-ictal global aphasia, right homonymous hemianopsia, right hemiparesis and hyperthermia $\left(38-39.6^{\circ} \mathrm{C}\right)$. Complete clinical workups during these events (including $\mathrm{C}$ reactive protein, sedimentation rate, leukocyte count, thorax radiograph, urinalysis, and lumber puncture) ruled out an infection. Brain magnetic resonance imaging and computerized tomography showed old lacunar basal ganglia infarcts and generalized atrophy. Electroencephalogram (EEG) obtained in two of these episodes revealed in one of them slow background activity of 6-7 Hz, with continuous slow theta/ delta activity in left fronto-temporal region, with paroxysmal activity (spikes and sharp waves) in the same localization. The patient was treated with valproate and antipyretics (paracetamol and lysine acetylsalicylate). The hyperthermia did not respond to these drugs, but resolved spontaneously in 12-18 hours and the neurological deficits recovered within 24 hours.

\section{DISCUSSION}

Transient post-ictal hyperthermia may follow generalized convulsive status epilepticus ${ }^{23}$. In our case, over four years of follow-up, the patient presented three episodes of right focal motor seizures with consciousness impairment and a prolonged post-critic with aphasia, right homonymous hemianopsia, right hemiparesis, and hyperthermia. There was no fever preceding seizures or convulsive status epilepticus. In all of them, an infectious cause of hyperthermia was exhaustively investigated. Such research was always negative. Therefore, we interpreted hyperthermia as a post-ictal manifestation.

Post-ictal hyperthermia seems to be a quite infrequent symptom and it has been rarely described ${ }^{2}$. Rossetti et al. ${ }^{2}$ reported two cases and reviewed the literature of the last 40 years. They found another eight reports of peri-ictal fever, which were mainly related to non-convulsive seizures, involving all age groups (5-83 years old), display a relatively short duration (8-96 hours) and showed mostly bi-temporal EEG alterations.

The exact mechanisms that underlie the onset of hyperthermia in the peri-ictal period are not well established. It seems possible that the thermoregulatory center in the hypothalamic pre-optic area may be affected by spreading epileptic activity, and thus cause elevated body temperature ${ }^{3-5}$. The mesial temporal lobe structures have extensive connections with the neuroendocrine hypothalamus portion, and a discharging temporal focus can possibly alter hypothalamic function ${ }^{3}$. Another mechanism may involve vagal nerve nuclei (nucleus tractus solitarius) modulation during seizures ${ }^{2}$. Seizure-induced production of pyrogens in several brain regions, such as neocortex, amygdala, and hippocampus, appears as an alternative ${ }^{2}$.

The knowledge of the existence of post-ictal hyperthermia could improve the medical management of subjects presenting with. Indeed, fever does not always imply infection, inflammation or malignancy, even though they are still the most common causes ${ }^{4}$. Whilst a seizure occurring in a febrile context should generally prompt investigations to detect an infectious etiology, repetitive occurrence of this feature should raise the suspicion of a post-ictal symptom. 
1. Kang J, Shen W, Macdonald R. Why does fever trigger febrile seizures? $\mathrm{GABA}_{\mathrm{A}}$ receptor $\gamma 2$ subunit mutations associated with idiopathic generalized epilepsies have temperature-dependent trafficking deficiencies. J Neurosci 2006;26:2590-2597.

2. Rossetti A, Tosi C, Despland P, Staedler C. Post-ictal fever: a rare symptom of partial seizures. Eur J Neurol 2007;14:586-590.
El-Ad B, Neufeld M. Periodic febrile confusion as a presentation of complex status epilepticus. Acta Neurol Scand 1990;82:350-352.

4. Chan K. Epilepsy - another cause of intermittent fever with confusion. Postgrad Med J 1992;68:119-120.

5. Meo R, Bilo L, Striano S, Ruosi P, Estraneo A, Nocerino C. Transient global amnesia of epileptic origin accompanied by fever. Seizure 1995;4:311-317.

\title{
Hopkins verbal learning test-revised and brief visuospatial memory test-revised: preliminary normative data for the Brazilian population
}

\author{
Hopkins verbal learning test-revised e brief visuospatial memory test-revised: referencial \\ normativo preliminar para a população brasileira
}

\section{Eliane Correa Miotto', Kenia Repiso Campanholo², Melissa Machado Rodrigues², Valéria Trunkl Serrao², Mara C S de Lucia², Milberto Scaff}

\section{'Department of Neurology, Hospital das Clínicas, Universidade de São Paulo (USP), São Paulo SP, Brazil; \\ ${ }^{2}$ Psychology Division, Hospital das Clínicas, Universidade de São Paulo (USP), São Paulo SP, Brazil.}

Correspondence: Eliane Correa Miotto; Divisão de Neurologia Clínica; Departamento de Neurologia; Avenida Dr. Enéas de Carvalho Aguiar 255; 05403-900 São Paulo SP - Brasil; E-mail: ecmiotto@usp.br

Conflict of interest: There is no conflict of interest to declare.

Received 17 May 2012; Received in final form 28 May 2012; Accepted 06 June 2012

Memory functions are cognitive processes related to the ability to encode, store and retrieve information associated to the fronto-temporal neurocircuitry ${ }^{1}$. Episodic memory refers to the system that allows conscious recollection of personal events or episodes and their contexts (time and place) $)^{1}$. Clinical measures of episodic memory include immediate and delayed free recall and recognition of word lists and pictures. Amongst these measures, the Hopkins verbal learning test-revised ${ }^{2}$ (HVLT-R) and the brief visuospatial memory test-revised ${ }^{3}$ (BVMT-R) are used to assess verbal episodic memory and visuospatial episodic memory, respectively, both including immediate, delayed and recognition. Although they are adopted as measures of memory functions in clinical practice, there are no normative data for the Brazilian adult and elderly population. The aim of this study was to present preliminary normative data for the HVLT-R and BVMT-R in a sample of the Brazilian population.

\section{METHODS}

The study, carried out at Department of Neurology and Psychology Division, Central Institute, Hospital das Clínicas, Universidade de São Paulo, Medical School, included 1,108 adult and elderly participants (18 to 85 years old and 0 to 17 years of education) recruited from different states in Brazil (São Paulo, Minas Gerais, Rio de Janeiro, Paraná, Santa Catarina, Goiás, Bahia e Alagoas). Subjects with neurologic and psychiatric disorders were excluded after answering a semi-structured interview questionnaire. The inclusion criteria was (a) Mini-mental state examination score above the cutoff for cognitive impairment based on education ${ }^{4}$; (b) Independence on daily-life activities; and (c) Hospital anxiety and depression scale scores below the cutoff for anxiety and depression ${ }^{5}$. The HVLT-R and BVMT-R were administered according to the test manual instructions and, for both tests, Form I was used. For HVLT-R, participants were instructed to memorize a list of 12 words (nouns) drawn from 3 semantic categories (precious stones, animals and human dwellings). The test includes an immediate recall derived from three learning trials, a delayed recall trail (after 20-25 min) and a yes/no delayed recognition trial. For BVMT-R, six geometric visual designs were shown to the participants for 10 seconds and after that, they were asked to reproduce as many of the designs as possible in the same location. This test includes an immediate recall derived from the three learning trials, a delayed recall (25 minutes) and a recognition trial.

Descriptive analyses and non-parametric tests using SigmaStat 3.5 (Kruskal-Wallis, Mann Whitney and post-hoc test using Muller-Dunn) were performed in order to investigate the influence of age, education, and gender on test performance. Statistical significance was established at 0.05 . 